\title{
Generation mean analysis for quantitative traits in sesame (Sesamum indicum L.) crosses
}

\author{
Vijayarajan Sharmila, Siruthaiyur Krishnamoorthy Ganesh and Mahalingam Gunasekaran \\ Department of Plant Breeding and Genetics, Agricultural College and Research Institute, Madurai, \\ Tamil Nadu, India
}

\begin{abstract}
To study the nature and magnitude of gene effects for yield and its components in sesame (Sesamum indicum L.) we carried out generation mean analysis using the following four crosses of different sesame cultivars: VS $9510 \times$ Co1; NIC 7907 x TMV 3; Cianno 13/10x VRI 1; and Si 1115/1 x TMV 3. The $P_{1}, P_{2}, F_{1}, F_{2}, B C_{1}$ and $B C_{2}$ of these generations were studied for seven quantitative traits. The analysis showed the presence of additive, dominance and epistatic gene interactions. The additive dominance model was adequate for plant height in the NIC $7907 \times$ TMV3 and Si 1115/1x TMV 3 crosses and for capsule length in the VS 9510 x Co1, NIC 7907 x TMV 3 and Si 1115/1 x TMV 3 crosses. An epistatic digenic model was assumed for the remaining crosses. Duplicate-type epistasis played a greater role than complementary epistasis. The study revealed the importance of both additive and non-additive types of gene action for all the traits studied.
\end{abstract}

Key words: Sesame, quantitative trait, scaling tests, gene effects, bi-parental mating.

Received: December 13, 2005; Accepted: July 28, 2006.

\section{Introduction}

Sesame (Sesamum indicum L.) is an ancient and important oil seed crop also known in India as til, ellu, beniseed, simsim and Sesame is often referred to by the epithet "the queen of oil seeds " because it is prized not only for its nutritive value but also for the quality and quantity ( $44 \%$ to $52 \%$ ) of its oil which is rich in vitamin $\mathrm{E}$ and has a significant amount of linoleic acid that can control blood cholesterol levels. The protein content of sesame seed is about $26.25 \%$ and the sulfur-containing amino acid methionine is present at a concentration of about 3.4\% (Mosjidis, 1982). Sesame seed oil is resistant to oxidation and rancidity under normal storage conditions. Production of sesame hybrids can be accomplished either genetically using the cytoplasmic male sterility system, which have not been yet reported in sesame, or non-genetically by manual emasculation and crossing for the production of hybrids, which is the preferred route due to the fact that sesame has epipetalous stamens. Emasculation is the simplest crossing technique for producing sesame F1 hybrids it might be feasible to use this technique to produce hybrids and obtain a quantum jump in yield with minimal cost. In practice, how-

Send correspondence to V. Sharmila. Senior Research Fellow, Department of Pulses, Centre for Plant Breeding and Genetics, Tamil Nadu Agricultural University, Coimbatore, 641003 Tamil Nadu, India. Email: shanagri@yahoo.co.in. ever, this technique has not contributed much to the current oil seed scenario, with the average sesame productivity in India being practically stagnant during last few years and not impressive as compared to other sesame growing countries of the world. So the challenge of the Indian sesame breeder is to step up yield through genetic improvement by adopting different breeding methodologies. For genetic improvement of the crop, the breeding method to be adopted depends mainly on the nature of gene action involved in the expression of quantitative trait. Line x Tester ( $\mathrm{L}$ T ) analysis is used to select the parents based on their combining ability but fails to detect the epistasis, which remains the most complex problem and on which it is extremely difficult to obtain reliable results. The presence or absence of epistasis can be detected by the analysis of generation means using the scaling test, which measures epistasis accurately whether it is complimentary (Additive $\mathrm{x}$ Additive) or duplicate (Additive $\mathrm{x}$ Dominance) and (Dominance $\mathrm{x}$ Dominance) at the digenic level. The objectives of this research described in this paper were to obtain information on the nature of gene action in sesame to provide a basis for an evaluation of selection methods for the improvement of the sesame population.

\section{Material and Methods}

We used eight Sesamum indicum L. cultivars (VS 9510, Co 1, NIC 7907, TMV 3, Cianno 13/10, VRI 1, Si 
1115/1 and TMV 3) provided by Regional Research Station, Vridhachalam, Tamil Nadu, India. The experiments involved the six basic generations (the $\mathrm{P}_{1}$ and $\mathrm{P}_{2}$ parent cultivars, the $\mathrm{F}_{1}$ and $\mathrm{F}_{2}$ first and second filial generations, and the $\mathrm{BC}_{1}$ and $\mathrm{BC}_{2}$ first and second back crosses) of four combinations of the parental cultivars, these combinations being VS 9510 x Co 1, NIC 7907 x TMV 3, Cianno 13/10 x VRI 1 and Si 1115/1 x TMV 3. The segregating and non-segregating parental populations were cultivated in a Randomized block design with two replications at the Agricultural College and Research Institute, Madurai, India during the winter of 2003. We used the parents of the respective crosses as the male parent and the $\mathrm{F}_{1}$ generation as the female parent and effected back crosses to produce the $\mathrm{B}_{1}\left(\mathrm{~F}_{1}\right.$ back crossed to $\left.\mathrm{P}_{1}\right)$ and $\mathrm{B}_{2}\left(\mathrm{~F}_{1}\right.$ back crossed to $\left.\mathrm{P}_{2}\right)$ generations and the $F_{1}$ hybrids were selfed to obtain $F_{2}$ seeds. All these generations were produced during two cropping seasons and, as such, all the six generations had to be grown together during the same cropping season. The row-length was always three meters but the number of rows varied as follows: three rows, for the non-segregating $\mathrm{P}_{1}, \mathrm{P}_{2}$ and $\mathrm{F}_{1} ; 40$ rows for the $\mathrm{F}_{2}$; and 20 rows for the $\mathrm{BC}_{1}$ and $\mathrm{BC}_{2}$ generations. Since the non-segregating generations represent the homogeneous population while the segregating generations represent the heterogeneous population the sample size (i.e. number of plants analyzed) varied as follows: 30 plants for the $\mathrm{P}_{1}, \mathrm{P}_{2}$ and $\mathrm{F}_{1}$ generations; 400 plants for the $\mathrm{F}_{2}$ generations; and 200 plants in the $\mathrm{BC}_{1}$ and $\mathrm{BC}_{2}$ generations. The traits assessed were days to maturity, plant height $(\mathrm{cm})$, number of branches per plant, number of capsules per plant, capsule length $(\mathrm{cm})$, weight $(\mathrm{g})$ of 1000 seeds and seed yield per plant ( $\mathrm{g}$ ).

The mean values, standard errors and variances of the different generations were subjected to weighed least-squares analysis using the scaling test (Mather 1949) and the joint scaling test to estimate gene effects. The genetic effects were estimated using the models suggested by Mather and Jinks (1971) and Jinks and Jones (1958). The significance of the scales and gene effects were tested by using the t-test (Singh and Chaudhary, 1985).

The A, B and C scaling tests were carried out for seven traits indicated the presence of non-allelic interactions in almost all cases. The A and $\mathrm{B}$ scaling tests provided the evidence for the presence of additive $\mathrm{x}$ additive $(i)$, additive $\mathrm{x}$ dominance $(j)$ and dominance $\mathrm{x}$ dominance $(l)$ type gene interactions. The $\mathrm{C}$ scaling test provided a test for type 1 epistasis. The type of epistasis was determined only when dominance $(h)$ and dominance $\mathrm{x}$ dominance $(l)$ effects were significant, when these effects had the same sign the effects were complementary while different signs indicated duplicate epistasis (Kearsey and Pooni, 1996).

\section{Results and Discussion}

The mean and standard error of the six generations with four crosses for seven traits are presented in Table 1, with the means values for the scaling joint scaling tests and their interaction effects being presented in Table 2 .

The hybrids performed better than their respective parents in all crosses except for the VS $9510 \mathrm{x}$ Co 1 cross in regard to the number of seed capsules per plant and for the NIC $7907 \times$ TMV 3 cross in regard to capsule length, both these crosses showing inferior performance than their respective $\mathrm{P}_{1}$ generations. In general, however, the trait mean values for the $\mathrm{F}_{1}$ and $\mathrm{F}_{2}$ generations were higher than the corresponding values for the $\mathrm{BC}_{1}$ and $\mathrm{BC}_{2}$ generations, while the values for the $\mathrm{F}_{2}$ generation were lower than the corresponding values for the $\mathrm{F}_{1}$ generation. The mean performance of the $\mathrm{BC}_{2}$ segregating generation was lower than that of the $\mathrm{BC}_{1}$ generation for all crosses and traits except for plant height and number of branches per plant for the $\mathrm{Si}$ 1115/1 x TMV 3 cross, number of capsules per plant and capsule length for the VS $9510 \times$ Co 1 cross, and seed yield per plant and the weight in grams of 1000 seeds for the VS 9510 x Co 1, Cianno 13/10 x VRI 1 and Si 1115/1 x TMV 3 crosses. The expected mean $(m)$ of the four possible homozygotes was positive and significant in all the crosses for all the traits.

A simple additive/dominance model was adequate as inferred from the non-significance of all the scales for plant height in the NIC 7907 x TMV 3 and Si 1115/1 x TMV 3 crosses, capsule length for the VS 9510 x Co 1, NIC $7907 \mathrm{x}$ TMV 3 and Si 1115/1 x TMV 3 crosses, and seed yield per plant for the NIC 7907 x TMV 3 cross. For the remaining crosses, an epistatic digenic interaction was found to be a suitable fit, since the scaling and/or joint scaling tests were significant.

The additive, dominance and epistatic types of gene interaction in each cross for different trait were found to be different from each other. The dominance $\mathrm{x}$ dominance $(l)$ interaction was larger than the additive $\mathrm{x}$ additive $(i)$ and additive $\mathrm{x}$ dominance $(j)$ effects put together, while for the main effects the dominance component $(h)$ was greater than the additive $(d)$ component. The dominance $(h)$ and dominance $\mathrm{x}$ dominance $(l)$ effects were in the opposite direction, suggesting that duplicate-type epistasis occurred in most cases and indicating predominantly dispersed alleles at the interacting loci (Jinks and Jones 1958). Dominance gene effects were found to be relatively more important, as indicated by the fact that in all cases the dominance ( $h$ )values were higher than the additive $(d)$ values.

The 'days to maturity' trait for the NIC 7907 x TMV 3 cross showed a pronounced additive, dominance and non-allelic interaction additive $\mathrm{x}$ dominance $(j)$ type gene interaction while the Cianno 13/10 x VRI 1 cross showed an dominance $\mathrm{x}$ dominance $(l)$ type interaction for the same trait. For the this trait the additive $(d)$, dominance $(h)$ and dominance $\mathrm{x}$ dominance $(l)$ gene interaction were found to play a major role. Duplicate epistasis for this trait has also been reported by Pathak and Dixit (1988). 
Table 1 - Mean and their standard error of six generations with four crosses for seven traits.

\begin{tabular}{|c|c|c|c|c|}
\hline Generation and trait & VS9501 X CO1 & NIC7907 X TMV3 & Cianno 13/10 x VRI 1 & Si $1115 / 1 \times$ TMV 3 \\
\hline \multicolumn{5}{|l|}{ Days to maturity } \\
\hline $\mathrm{P}_{1}$ & $99.90 \pm 1.33$ & $77.66 \pm 0.61$ & $105.33 \pm 0.80$ & $93.19 \pm 1.48$ \\
\hline $\mathrm{P}_{2}$ & $102.2 \pm 0.81$ & $90.69 \pm 1.08$ & $102.26 \pm 0.81$ & $90.69 \pm 1.08$ \\
\hline $\mathrm{F}_{1}$ & $102.46 \pm 0.27$ & $102.47 \pm 0.44$ & $103.46 \pm 0.25$ & $107.42 \pm 0.29$ \\
\hline $\mathrm{F}_{2}$ & $103.3 \pm 0.26$ & $100.48 \pm 0.44$ & $103.44 \pm 0.26$ & $102.42 \pm 0.29$ \\
\hline \multirow{2}{*}{$\begin{array}{l}\mathrm{B}_{1} \\
\mathrm{~B}_{2}\end{array}$} & $101.25 \pm 0.25$ & $99.32 \pm 0.42$ & $101.25 \pm 0.25$ & $100.81 \pm 0.27$ \\
\hline & $102.23 \pm 0.35$ & $102.24 \pm 0.36$ & $102.24 \pm 0.35$ & $102.24 \pm 0.35$ \\
\hline \multicolumn{5}{|l|}{ Plant height $(\mathrm{cm})$} \\
\hline $\mathrm{P}_{1}$ & $117.33 \pm 1.77$ & $100.93 \pm 1.83$ & $91.60 \pm 1.22$ & $95.56 \pm 2.02$ \\
\hline $\mathrm{P}_{2}$ & $109.26 \pm 1.81$ & $108.06 \pm 3.21$ & $97.06 \pm 1.80$ & $94.36 \pm 2.21$ \\
\hline $\mathrm{F}_{1}$ & $128.20 \pm 1.60$ & $118.53 \pm 2.98$ & $99.46 \pm 1.91$ & $131.00 \pm 2.98$ \\
\hline $\mathrm{F}_{2}$ & $112.98 \pm 2.65$ & $104.91 \pm 1.79$ & $102.35 \pm 3.21$ & $113.50 \pm 1.96$ \\
\hline $\mathrm{B}_{1}$ & $116.60 \pm 2.01$ & $115.66 \pm 1.78$ & $101.93 \pm 1.83$ & $105.23 \pm 1.79$ \\
\hline & $87.73 \pm 2.78$ & $111.50 \pm 1.76$ & $96.90 \pm 2.7$ & $110.30 \pm 1.61$ \\
\hline \multicolumn{5}{|l|}{ Branches per plant } \\
\hline $\mathrm{P}_{1}$ & $4.86 \pm 0.30$ & $4.00 \pm 0.30$ & $3.80 \pm 0.03$ & $2.60 \pm 0.30$ \\
\hline $\mathrm{P}_{2}$ & $6.00 \pm 0.22$ & $4.33 \pm 0.17$ & $3.90 \pm 0.02$ & $2.86 \pm 0.22$ \\
\hline $\mathrm{F}_{1}$ & $6.80 \pm 0.17$ & $5.00 \pm 0.24$ & $5.30 \pm 0.06$ & $4.06 \pm 0.20$ \\
\hline $\mathrm{F}_{2}$ & $5.10 \pm 0.14$ & $4.13 \pm 0.17$ & $5.50 \pm 0.06$ & $2.43 \pm 0.17$ \\
\hline $\mathrm{B}_{1}$ & $3.70 \pm 0.22$ & $3.83 \pm 0.21$ & $5.26 \pm 0.10$ & $2.30 \pm 0.06$ \\
\hline $\mathrm{B}_{2}$ & $4.50 \pm 0.17$ & $3.47 \pm 0.26$ & $4.40 \pm 0.07$ & $3.13 \pm 0.28$ \\
\hline \multicolumn{5}{|l|}{ Capsules per plant } \\
\hline $\mathrm{P}_{1}$ & $43.20 \pm 1.9$ & $41.83 \pm 3.59$ & $98.73 \pm 1.17$ & $31.73 \pm 3.49$ \\
\hline $\mathrm{P}_{2}$ & $104.03 \pm 6.16$ & $58.93 \pm 3.50$ & $83.26 \pm 1.30$ & $50.70 \pm 4.02$ \\
\hline $\mathrm{F}_{1}$ & $102.19 \pm 8.63$ & $101.26 \pm 4.02$ & $106.63 \pm 2.7$ & $133.86 \pm 7.6$ \\
\hline $\mathrm{F}_{2}$ & $78.87 \pm 2.45$ & $87.66 \pm 3.15$ & $74.01 \pm 1.9$ & $67.09 \pm 2.2$ \\
\hline $\mathrm{B}_{1}$ & $53.97 \pm 1.79$ & $73.72 \pm 2.29$ & $67.20 \pm 2.48$ & $43.22 \pm 1.6$ \\
\hline $\mathrm{B}_{2}$ & $67.62 \pm 2.68$ & $64.57 \pm 3.32$ & $53.75 \pm 2.00$ & $43.49 \pm 1.44$ \\
\hline \multicolumn{5}{|l|}{ Capsule length $(\mathrm{cm})$} \\
\hline $\mathrm{P}_{1}$ & $2.33 \pm 0.01$ & $3.09 \pm 0.01$ & $1.84 \pm 0.01$ & $2.30 \pm 0.01$ \\
\hline $\mathrm{P}_{2}$ & $2.34 \pm 0.02$ & $2.32 \pm 0.04$ & $2.08 \pm 0.01$ & $2.34 \pm 0.01$ \\
\hline $\mathrm{F}_{1}$ & $2.42 \pm 0.01$ & $2.94 \pm 0.02$ & $2.25 \pm 0.02$ & $2.42 \pm 0.01$ \\
\hline $\mathrm{F}_{2}$ & $2.40 \pm 0.02$ & $2.81 \pm 0.09$ & $2.10 \pm 0.01$ & $2.40 \pm 0.06$ \\
\hline $\mathrm{B}_{1}$ & $2.38 \pm 0.05$ & $3.04 \pm 0.004$ & $2.27 \pm 0.04$ & $2.38 \pm 0.04$ \\
\hline $\mathrm{B}_{2}$ & $2.49 \pm 0.05$ & $2.65 \pm 0.06$ & $2.23 \pm 0.04$ & $2.49 \pm 0.04$ \\
\hline \multicolumn{5}{|c|}{ Weight of $10^{3}$ seeds (g) } \\
\hline $\mathrm{P}_{1}$ & $2.64 \pm 0.05$ & $2.61 \pm 0.10$ & $2.70 \pm 0.09$ & $2.20 \pm 0.09$ \\
\hline $\mathrm{P}_{2}$ & $3.39 \pm 0.04$ & $3.22 \pm 0.08$ & $3.34 \pm 0.06$ & $3.34 \pm 0.09$ \\
\hline $\mathrm{F}_{1}$ & $3.92 \pm 0.06$ & $3.86 \pm 0.14$ & $3.72 \pm 0.04$ & $3.47 \pm 0.10$ \\
\hline $\mathrm{F}_{2}$ & $3.77 \pm 1.33$ & $3.34 \pm 0.06$ & $3.63 \pm 0.05$ & $3.72 \pm 0.04$ \\
\hline $\mathrm{B}_{1}$ & $3.10 \pm 0.05$ & $3.77 \pm 0.06$ & $3.75 \pm 0.04$ & $3.11 \pm 0.05$ \\
\hline $\mathrm{B}_{2}$ & $3.77 \pm 0.06$ & $3.89 \pm 0.05$ & $3.59 \pm 0.08$ & $3.93 \pm 0.06$ \\
\hline \multicolumn{5}{|c|}{ Seed yield per plant (g) } \\
\hline $\mathrm{P}_{1}$ & $20.90 \pm 0.32$ & $20.10 \pm 0.26$ & $11.53 \pm 0.28$ & $14.80 \pm 0.26$ \\
\hline $\mathrm{P}_{2}$ & $25.57 \pm 0.23$ & $21.01 \pm 0.28$ & $23.17 \pm 0.26$ & $21.01 \pm 0.28$ \\
\hline $\mathrm{F}_{1}$ & $40.68 \pm 0.41$ & $32.12 \pm 0.26$ & $30.13 \pm 0.48$ & $32.12 \pm 0.26$ \\
\hline $\mathrm{F}_{2}$ & $25.29 \pm 0.39$ & $25.03 \pm 0.28$ & $18.04 \pm 0.77$ & $25.03 \pm 0.28$ \\
\hline $\mathrm{B}_{1}$ & $19.72 \pm 0.31$ & $26.17 \pm 1.5$ & $14.61 \pm 1.01$ & $20.82 \pm 0.37$ \\
\hline $\mathrm{B}_{2}$ & $24.21 \pm 0.48$ & $25.08 \pm 0.41$ & $18.05 \pm 1.07$ & $25.07 \pm 0.41$ \\
\hline
\end{tabular}

In the case of the plant height trait the additive $\mathrm{x}$ dominance $(j)$ and dominance $\mathrm{x}$ dominance $(l)$ effects were significant in the VS $9510 \times$ Co 1 cross, while the additive $\mathrm{x}$ dominance $(j)$ effect was significant only in the Cianno 13/10 x VRI 1 cross. This trait also showed duplicate-type epistasis in all cases. The dominance $\mathrm{x}$ dominance $(l)$ non- allelic interaction was higher than either the dominance $(h)$ or additive $(d)$ effects. Although additive $(d)$ and additive $\mathrm{x}$ additive $(i)$ gene effects were significant for the 'plant height' trait non-additive gene effects appear to have been more important. Ganesh (1999) reported duplicate epistasis for this trait. 
Table 2 - Means \pm standard error and scaling test and genetic effects for different sesame traits.

\begin{tabular}{|c|c|c|c|c|c|c|c|c|c|c|}
\hline Cross & A & B & $\mathrm{C}$ & $\hat{m}$ & {$[\hat{d}]$} & {$[\hat{h}]$} & {$[\hat{i}]$} & {$[\hat{j}]$} & {$[\hat{l}]$} & $\begin{array}{r}\text { Type of } \\
\text { Epistasis }\end{array}$ \\
\hline \multicolumn{11}{|c|}{ Days to maturity } \\
\hline $\mathrm{C}_{1}$ & - & - & $*$ & $106.29 * \pm 1.59$ & $-1.18 \pm 1.78$ & $-10.41 * \pm 4.41$ & $-5.84 * \pm 1.38$ & $0.20 \pm 0.89$ & $5.99 \pm 3.30$ & $\mathrm{D}$ \\
\hline $\mathrm{C}_{2}$ & $*$ & * & * & $82.72 * \pm 2.17$ & $6.71 * \pm 0.62$ & $51.27^{*} \pm 5.19$ & $1.21 \pm 2.08$ & $3.85^{*} \pm 0.83$ & $-31.53^{*} \pm 3.71$ & $\mathrm{D}$ \\
\hline $\mathrm{C}_{3}$ & $*$ & - & - & $110.48 * \pm 1.45$ & $1.53 * \pm 0.57$ & $-20.27 * \pm 3.72$ & $-6.86 * \pm 1.33$ & $-2.52 * \pm 0.72$ & $12.22 * \pm 3.10$ & $\mathrm{D}$ \\
\hline $\mathrm{C}_{4}$ & $*$ & $*$ & $*$ & $95.53^{*} \pm 1.75$ & $1.25 \pm 0.92$ & $20.63^{*} \pm 4.52$ & $-3.58 * \pm 1.48$ & $-2.67 * \pm 1.02$ & $-13.70 * \pm 3.50$ & $\mathrm{D}$ \\
\hline \multicolumn{11}{|c|}{$\begin{array}{l}\text { Plant height } \\
(\mathrm{cm})\end{array}$} \\
\hline $\mathrm{C}_{1}$ & - & $*$ & $*$ & $156.86^{*} \pm 16.76$ & $-3.74 * \pm 2.35$ & $-146.85^{*} \pm 42.41$ & $-43.26 * \pm 16.63$ & $32.60^{*} \pm 6.13$ & $118.19^{*} \pm 26.63$ & $\mathrm{D}$ \\
\hline $\mathrm{C}_{2}$ & - & - & - & $69.70 * \pm 20.48$ & $-3.56 \pm 2.12$ & $92.02 \pm 51.78$ & $34.80 \pm 20.38$ & $7.67 \pm 7.3$ & $-43.19 \pm 32.28$ & $\mathrm{D}$ \\
\hline $\mathrm{C}_{3}$ & $*$ & - & $*$ & $108.46^{*} \pm 6.63$ & $-2.70 * \pm 1.26$ & $-9.30 \pm 16.26$ & $-14.09 * \pm 6.51$ & $5.42 * \pm 2.37$ & $0.31 \pm 10.9$ & $\mathrm{D}$ \\
\hline $\mathrm{C}_{4}$ & - & - & - & $117.90 * \pm 6.27$ & $-0.60 \pm 0.22$ & $-30.70 \pm 0.69$ & $-22.94 \pm 1.23$ & $-5.67 \pm 0.96$ & $43.80 \pm 1.56$ & $\mathrm{D}$ \\
\hline \multicolumn{11}{|c|}{ Number of branches per plant } \\
\hline $\mathrm{C}_{1}$ & $*$ & $*$ & $*$ & $9.43 * \pm 0.98$ & $-0.57 * \pm 0.20$ & $-14.69^{*} \pm 2.50$ & $-4.0 * \pm .096$ & $-0.23 \pm 0.39$ & $12.06 * \pm 1.60$ & $\mathrm{D}$ \\
\hline $\mathrm{C}_{2}$ & $*$ & * & - & $6.07 * \pm 1.01$ & $-0.17 \pm 1.40$ & $-6.74 * \pm 2.45$ & $-1.92 \pm 1.00$ & $0.53 \pm 0.33$ & $5.67 * \pm 1.57$ & $\mathrm{D}$ \\
\hline $\mathrm{C}_{3}$ & $*$ & - & * & $6.74 * \pm 0.44$ & $-0.01 \pm 0.23$ & $-3.30^{*} \pm 1.17$ & $-2.91 * \pm 0.43$ & $0.94 * \pm 0.19$ & $1.89 * \pm 0.82$ & $\mathrm{D}$ \\
\hline $\mathrm{C}_{4}$ & $*$ & - & $*$ & $1.59 \pm 0.18$ & $-0.13 \pm 0.25$ & $0.89 \pm 2.28$ & $-1.14 \pm 0.77$ & $-0.70 \pm 0.42$ & $1.58 \pm 1.59$ & $\mathrm{C}$ \\
\hline \multicolumn{11}{|c|}{ Number of capsules per plant } \\
\hline $\mathrm{C}_{1}$ & $*$ & $*$ & - & $145.93 * \pm 12.59$ & $-30.41 * \pm 3.23$ & $-224.51 * \pm 29.25$ & $-72.31 * \pm 11.76$ & $16.77 * \pm 4.5$ & $180.77 * \pm 24.56$ & $\mathrm{D}$ \\
\hline $\mathrm{C}_{2}$ & - & * & * & $124.42 * \pm 15.17$ & $-8.55 * \pm 2.51$ & $-124.01 * \pm 35.72$ & $-74.08 * \pm 14.95$ & $17.69 * \pm 4.75$ & $100.80 * \pm 22.56$ & $\mathrm{D}$ \\
\hline $\mathrm{C}_{3}$ & $*$ & $*$ & $*$ & $145.16^{*} \pm 10.01$ & $7.73 * \pm 0.90$ & $-246.04 * \pm 24.67$ & $-54.16 * \pm 9.96$ & $5.72 \pm 3.32$ & $207.52^{*} . \pm 15.94$ & $\mathrm{D}$ \\
\hline $\mathrm{C}_{4}$ & $*$ & $*$ & $*$ & $136.16^{*} \pm 10.10$ & $-9.50 * \pm 2.66$ & $-273.90 * \pm 23.50$ & $-94.93 * \pm 9.80$ & $-9.23 * \pm 3.44$ & $271.6^{*} \pm 20.3$ & $\mathrm{D}$ \\
\hline \multicolumn{11}{|c|}{ Capsule length $(\mathrm{cm})$} \\
\hline $\mathrm{C}_{1}$ & - & - & - & $2.19 * \pm 0.26$ & $-.005 \pm 0.035$ & $0.59 \pm 0.76$ & $0.17 \pm 0.27$ & $-0.11 \pm 0.12$ & $-0.37 \pm 0.51$ & $\mathrm{D}$ \\
\hline $\mathrm{C}_{2}$ & - & - & - & $2.51^{*} \pm 0.16$ & $0.39 * \pm 0.03$ & $0.61 \pm 0.38$ & $0.14 \pm 0.16$ & $0.05 \pm 0.05$ & $-0.23 \pm 0.24$ & $\mathrm{D}$ \\
\hline $\mathrm{C}_{3}$ & $*$ & - & $*$ & $1.43^{*} \pm 0.07$ & $-0.12 * \pm 0.03$ & $1.65^{*} \pm 0.17$ & $0.54 * \pm 0.06$ & $0.16^{*} \pm 003$ & $-0.82 * \pm 0.11$ & $\mathrm{D}$ \\
\hline $\mathrm{C}_{4}$ & - & - & - & $2.19 * \pm 0.29$ & $-0.01 \pm 0.03$ & $0.62 \pm 0.76$ & $0.14 \pm 0.27$ & $-0.10 \pm 0.12$ & $-0.37 \pm 0.51$ & $\mathrm{D}$ \\
\hline \multicolumn{11}{|c|}{1000 seed weight $(\mathrm{g})$} \\
\hline $\mathrm{C}_{1}$ & - & - & $*$ & $3.02 * \pm 0.25$ & $0.29 * \pm 5.24$ & $1.57 * \pm 0.65$ & $0.66 * \pm 0.24$ & $0.08 \pm 0.20$ & $-0.14 \pm 0.46$ & $\mathrm{D}$ \\
\hline $\mathrm{C}_{2}$ & - & - & * & $3.02 * \pm 0.25$ & $-0.31 * \pm 0.08$ & $1.92 * \pm 0.64$ & $0.90 * \pm 0.24$ & $-0.05 \pm .22$ & $-0.452 * \pm 0.43$ & $\mathrm{D}$ \\
\hline $\mathrm{C}_{3}$ & - & - & * & $2.32 * \pm 0.25$ & $0.18 * \pm 0.07$ & $3.45^{*} \pm 0.659$ & $1.21 * \pm 0.24$ & $0.00+0.21$ & $-1.36^{*} \pm 0.45$ & $\mathrm{D}$ \\
\hline $\mathrm{C}_{4}$ & - & - & $*$ & $3.38^{*} \pm 0.29$ & $0.47^{*} \pm 0.08$ & $0.62 \pm 0.77$ & $0.42 \pm 0.28$ & $0.12 \pm 0.26$ & $0.24 \pm 0.53$ & $\mathrm{C}$ \\
\hline \multicolumn{11}{|c|}{ Seed yield per plant (g) } \\
\hline $\mathrm{C}_{1}$ & $*$ & $*$ & $*$ & $36.94 * \pm 1.94$ & $-2.33 * \pm 0.20$ & $-49.90 * \pm 4.66$ & $-13.70 * \pm 1.93$ & $-2.16^{*} \pm 0.60$ & $53.64 * \pm 2.90$ & $\mathrm{D}$ \\
\hline $\mathrm{C}_{2}$ & - & * & * & $18.18 * \pm 3.34$ & $-0.45 * \pm 0.19$ & $13.47 \pm 9.69$ & $2.38 \pm 3.33$ & $1.55 \pm 1.58$ & $0.47 \pm 6.41$ & $\mathrm{C}$ \\
\hline $\mathrm{C}_{3}$ & $*$ & $*$ & $*$ & $24.19^{*} \pm 4.28$ & $-5.82 * \pm 0.23$ & $-30.53 * \pm 10.83$ & $-6.84 \pm 4.27$ & $2.38 \pm 1.50$ & $36.46 * \pm 6.70$ & $\mathrm{D}$ \\
\hline $\mathrm{C}_{4}$ & $*$ & * & - & $26.24 * \pm 1.60$ & $-3.10 * \pm 1.90$ & $-10.73^{*} \pm 4.07$ & $-8.33 * \pm 1.59$ & $-1.15^{*} \pm 0.59$ & $16.61 * \pm 2.58$ & $\mathrm{D}$ \\
\hline
\end{tabular}

Key: $\mathrm{C}_{1}=\mathrm{VS} 9510 \mathrm{CO} 1 ; \mathrm{C}_{2}=\mathrm{NIC} 7907 \mathrm{TMV} 3 ; \mathrm{C}_{3}=$ Cianno $13 / 10 \mathrm{VRI} 1 ; \mathrm{C}_{4}=\mathrm{Si} 1115 / 1 \mathrm{TMV} 3 ; \hat{m}=\operatorname{mid}$ point $[\hat{d}]=\operatorname{additive} ;[\hat{h}]=\operatorname{dominance} ;$ $[\hat{i}]=$ additive $\mathrm{x}$ additive; $[\hat{j}]=$ additive $\mathrm{x}$ dominance; $[\hat{l}]=$ dominance $\mathrm{x}$ dominance. An asterisk $(*)$ indicates that the value was significant by the $\mathrm{t}$-test at the $5 \%$ probability level.

For the 'number of branches per plant' trait the $l$ effect was found to be the most important in the VS $9510 \times \mathrm{Co}$ 1 and NIC $7907 \times$ TMV 3 crosses while for the Cianno $13 / 10 \times$ VRI 1 cross both additive $x$ dominance $(j)$ and dominance $\mathrm{x}$ dominance $(l)$ effects were significant. Duplicate-type epistasis was complementary in the Si $1115 / 1 \mathrm{x}$ TMV 3 cross. Duplicate type of epistasis was also reported for this trait by Kumar et al. (1998).

In regard to the 'number of capsules per plant' trait dominance gene effects were found to be relatively more important because of the dominance $(h)$ values were higher than the additive $(d)$ in three out of four cases and genes with negative effects were dominant over genes with positive effects. Non-allelic additive $\mathrm{x}$ dominance $(j)$ and dominance $\mathrm{x}$ dominance $(l)$ interactions and duplicate epistasis were observed for this trait. Additive gene action $(d)$ along with an dominance $\mathrm{x}$ dominance $(l)$ type interaction for this trait were found in the Cianno 13/10 x VRI 1 cross.

For the 'seed yield per plant' trait all the gene interaction effects were non-significant for the NIC 7907 x TMV 3 
cross, while the remaining three crosses showed type dominance $\mathrm{x}$ dominance $(l)$ effects. These results indicate that seed yield per plant is predominantly controlled by dominance $\mathrm{x}$ dominance $(l)$ type interaction effects. The dominance $(h)$ and dominance $\mathrm{x}$ dominance $(l)$ gene effects showed opposite signs, indicating the presence of duplicate dominant epistasis in the expression of this trait.

A additive $\mathrm{x}$ dominance $(j)$ type interaction was observed for the 'number of capsules per plant' and 'seed yield per plant' traits and the $h$ gene effect was found to be predominant in the expression of these traits. These findings are in good agreement with those of Deenamani and Dorairaj (1994) for the 'number of capsules per plant' trait and with Ganesh (1999) for the 'seed yield per plant' trait, who also reported duplicate epistasis for this trait. Only the Cianno 13/10 x VRI 1 cross showed $d, i$ and $j$ effects for capsule length, a simple additive-dominance model being adequate for the other three crosses To have a positive shift in the expression of the phenotypic mean it is essential to harness both the additive and non-additive gene effects prevalent in the 'capsule length' strength.

The 'weight per 1000 seeds' trait was additive and complementary for the Si 1115/1 x TMV 3 cross while additive $(d)$, dominance $\mathrm{x}$ dominance $(l)$ and additive $\mathrm{x}$ dominance $(j)$ effects and duplicate epistasis were important in the three other crosses. The $d, h$ and additive $\mathrm{x}$ additive $(i)$ type gene interactions indicate that this trait is under the control of both fixable and non-fixable gene effects. The additive $\mathrm{x}$ additive $(i)$ type gene interaction and duplicate epistasis seen in this trait suggest the possibilities of obtaining transgressive segregants in later generations.

The additive effects and gene interaction dominance $\mathrm{x}$ dominance $(l)$ or other type digenic complementry gene interaction can be exploited effectively by selection for the improvement the characters. Use of reciprocal recurrent selection or Bi-parental mating suggested to improve the characters when both additive and non- additive gene effects are involved in the expression of these traits. Presence of non-additive gene for days to maturity, number of branches per plant, number of seed capsule per plant and seed yield per plant indicating that conventional selection procedure may not be effective enough for improvement of yield. Therefore postponement of selection in later generations or intermating among the selected segregants fol- lowed by one or two generations of selfing could be suggested to break the undesirable linkage and allow the accumulation of favorable alleles for the improvement of this trait.

The different types of gene effects estimated provided a test for gene action and are useful for analyzing the genetic architecture of a crop so as to further improve desirable traits. The estimates obtained from each cross may be unique to that cross and may not be applicable to the parental population. Additive genetic variance formed the major part of the genetic variance for the important yield component 'weight per 1000 seeds' trait. Therefore genetic improvement in the 'seed yield per plant' trait would be easier through indirect selection for a component trait such as the 'weight per 1000 seeds' trait than through direct selection for seed yield itself.

\section{References}

Deenamani IE and Stephen Dorairaj M (1994) Genetics of quantitative characters associated with capsules in Sesamum indicum L. Madras Agric J 81:241-243.

Ganesh SK and Sakila M (1999) Generation mean analysis in sesame (Sesamum indicum L.) crosses. Sesame and Safflower Newsl 14:8-14.

Jinks JL and Jones RM (1958) Estimation of the components of heterosis. Genetics 43:223-224.

Kearsey MJ and Pooni HS (1996) The Genetic Analysis of Quantitative Traits.1st edition. Chapman and Hall, London.

Kumar ST, Thangavelu S and Sree Rangasmay SR (1998) Genetic analysis of seed size characters in sesame. (Sesamum indicum L.). Sesame and Safflower Newsl 13:26-32.

Mather K (1949) Biometrical Genetics. Mather and Co., London.

Mather K and Jinks JL (1971) Biometrical Genetics: The Study of Continuous Variations. Chapman and Hall Ltd., London, $382 \mathrm{pp}$.

Mosjidis JA (1982) The inheritance of oil content and its fatty acid composition in the sesame seed. (Sesamum indicum L.) and the study of their correlations. Diss Abstr Intermat B 42:3947B.

Pathak, HC and Dixit, SK (1988) Genetic analysis for single stemmed sesame (Sesamum indicum L.). Indian J Genet 48:325-330.

Singh RF and Chaudhary BD (1985) Biometrical Methods in Quantitative Genetic Analysis. Kalyani Publishers, New Delhi, 302 pp.

Associate Editor: Ernesto Paterniani 